\title{
Quality Properties of Ginseng Chicken Porridge Prepared with Individually Gamma Irradiated Raw Materials
}

\author{
Mee-Hye Shin ${ }^{1}$, In-Jun Han, and Ju-Woon Lee* \\ Advanced Radiation Technology Institute, Korea Atomic Energy Research Institute, Jeongeup 580-185, Korea \\ ${ }^{1}$ Department of Food Technology and Services, Eulji University, Sungnam 461-713, Korea
}

\begin{abstract}
This study was to establish irradiation process for serving ginseng chicken porridge to immune-compromised patients. Raw chicken, glutinous rice, ginseng, garlic, dried jujube and carrot were used as raw materials for ginseng chicken porridge. The initial level of microorganisms contaminated in raw materials and their predominant species were determined. The level of microorganism detected in raw chicken and in ginseng were 3.4 Log CFU/g and 4.7 Log CFU/g, respectively. Major predominant microorganisms were Pseudomonas fragi in chicken, Enterobactor faecalis in carrot, and Bacillus subtilis in other materials. Chicken and carrot were excluded from irradiation treatment because ordinary thermal treatment can inactivate the microorganisms contaminated in those materials. Five kGy of gamma ray was the effective sterilizing dose required to inactivate $B$. subtilis in glutinous rice, garlic and jujube, and $10 \mathrm{kGy}$ in ginseng. Ginseng chicken porridge was prepared with each of raw materials gamma-irradiated with the selected sterilizing doses. Control was ginseng chicken porridge prepared with non-irradiated materials. The growth of microorganisms was not observed in the chicken porridge prepared with irradiated raw materials. Sensory results showed that the score of flavor and off-flavor was slightly lower in ginseng chicken porridge prepared with irradiated raw materials than in control. This was considered to be due to the increase of TBARS values by gamma irradiation. However, there was no significant difference on overall acceptance between the porridge prepared with irradiated raw materials and control. The results showed that the individual gamma irradiation of raw materials can be applied to prepare ginseng chicken porridge as meals for the immunocompromised patients.
\end{abstract}

Key words: ginseng chicken porridge, gamma irradiation, immunocompromised patients, sterilized food

\section{Introduction}

Nutritional supply to immunocompromised patients should be considered with the nutritional requirement and rigid hygienic quality with very low contamination level $(<1.0 \mathrm{Log}$ CFU/10 g) of microorganisms of the served foods for their remediation and recovery (Richard and Walter, 1998). There is no choice but to apply severe processing methods such as heat treatment under high pressure and treatment of sanitary reagents to match hygienic condition and to improve malnutrition (Bruun et al., 1999; Edington et al., 2000; Waitzberg et al., 2001). However, as these methods accompany the deterioration of organoleptic quality or minimal nutrients of foods served for the patients (Al-Baali and Farid, 2006), alternative food

\footnotetext{
*Corresponding author: Ju-Woon Lee, Advanced Radiation Technology Institute, Korea Atomic Energy Research Institute, Jeongeup 580-185, Korea. Tel: 82-63-570-3204, Fax: 82-63570-3242, E-mail: sjwlee@kaeri.re.kr
}

processing methods minimizing the change has been required to supply commercial products for safe intake of immunocompromised patients (Zhang et al., 2003).

In Korea, ginseng chicken porridge is particularly popular for the diet of the elderly and the infirm, and also as a breakfast food. According to survey conducted in Korean retail market, chicken porridge was the most frequently consumed one among other porridges made with rice, red bean, mung bean, pumpkin, abalone, and pine nut (June et al., 1998). The common way to prepare ginseng chicken porridge is to cook chicken in water with white rice, ginseng and a variety of vegetables such as carrot, onion, pumpkin and scallion by thermal treatment. As ginseng chicken porridge is prepared using high protein chicken, high carbohydrate rice and lots of vegetables, it is known to be healthy, nutritious, and easily digestible food (Shin and Ryu, 2008). Therefore, porridges including ginseng chicken porridge have been applied to the initial supply and the improvement of nutrition for patients because of its high digestion ability (Bahwere et 
al., 2009; Han et al., 2011).

However, ordinary thermal treatment used for cooking ginseng chicken porridge cannot eliminate all microorganisms present in the food. One of the reason is the presence of thermo-stable bacteria (Bacillus sp.) contaminated in rice and other vegetables (Leff and Fierer, 2013; Oh et al., 2007), which is used for the preparation of various porridges. This make the thermal treatment difficult to meet the rigid hygienic quality required for immunocompromized patients. Therefore, it requires a combination with other food sanitary methods for the bacteria-free preparation of porridge served for immuno-compromised patients.

Irradiation technology has been considered as an effective sanitary method to prevent food poisoning by inactivating harmful pathogens and to extend the shelf life of foods reducing spoilage (Farkas, 2006). Unlike thermal treatment, this technology has relative economical and nutritional advantages. However, as irradiation technology can enhance the generation of off-flavor or accelerate lipid oxidation in foods when irradiated with a high dose (Kim et al., 2009; Park et al., 2010a; Park et al., 2010b), the irradiation dose or method applied should be effectively selected to alleviate the formation of off-flavor, considering to the initial contamination level and predominant species of microorganisms in target foods.

In this study, the initial level of microorganisms and major predominant species of raw materials used for the preparation of ginseng chicken porridge was investigated, and the effect of gamma-irradiation on the sensory quality of ginseng chicken porridge prepared with individually gamma-irradiated raw materials was evaluated.

\section{Materials and Methods}

\section{Materials}

Chicken (whole body), glutinous rice, ginseng, garlic, carrot, and jujube as raw materials for ginseng chicken porridge were purchased from local market in Jeongeupsi in South Korea. All materials were individually washed within tap water, and were cut with proper sizes prior to making ginseng chicken porridge. For the determination of the initial contamination level and the predominant species of microorganisms, two of $50 \mathrm{~g}$ of raw materials were individually vacuum packaged into an sterile aluminum-laminated low-density polyethylene (Al-LDPE, Sunkyung Co., Ltd., Korea), and stored in a refrigerator until tested.

\section{Gamma irradiation}

Glutinous rice, ginseng, garlic and jujube were irradiated in a cobalt-60 gamma irradiator (AECL, R-79, MDS Nordion Inc., Canada) at the Korea Atomic Energy Research Institute (Jeongeup, Korea). The source strength was approximately $11.1 \mathrm{PBq}$ with a dose rate of $10 \mathrm{kGy} /$ $\mathrm{hr}$, and the actual doses were within $2 \%$ of the target doses. The absorbed doses were measured using the alanine-EPR dosimetry system (ISO/ASTM 51607:2003) (ASTM, 2004).

\section{Preparation of ginseng chicken porridge}

The list of raw materials for ginseng chicken porridge was provided in Table 1 . The individually gamma-irradiated glutinous rice, ginseng, garlic and jujube, and nonirradiated chicken and carrot were used for the preparation of ginseng chicken porridge. Control was prepared with all non-irradiated raw materials. And, all cookery instruments (pot, wooden scoop, spoon and cheesecloth, etc) were autoclaved for sanitation. Washed chicken $(1,000 \mathrm{~g})$ was put into a pot with $4 \mathrm{~L}$ of deionized distilled water (DDW, w/w), boiled at $100^{\circ} \mathrm{C}$ for $2 \mathrm{~h}$, and cooled at room temperature. Meat were separated from cooked chicken, sliced to small size with about $0.5 \mathrm{~cm}$ of thickness, and stored at $4^{\circ} \mathrm{C}$. Chicken broth was filtered with 4 layers of cheesecloth for use of the porridge soup stock. Glutinous rice soaked in a DDW for $2 \mathrm{~h}$, sliced ginseng $(0.2$ $\mathrm{cm}$ of thickness), carrot cut $(0.3 \mathrm{~cm} \times 0.3 \mathrm{~cm})$, jujube, and about $3.9 \mathrm{~L}$ of chicken soup stock were put into the pot, and cooked at $100^{\circ} \mathrm{C}$ for $30 \mathrm{~min}$ by gently stirring with wooden scoop. Salt was added at the final step of cooking and the porridge samples were cooled at room temperature and used for subsequent experiments.

\section{Total bacterial population}

Total bacterial populations in raw materials and ginseng chicken porridge samples were determined using the method of Park et al. (2010a). In brief, $10 \mathrm{~g}$ of sample was

Table 1. Formula for preparing ginseng chicken porridge

\begin{tabular}{ccc}
\hline \hline Ingredient & Quantity $(\mathrm{g})$ & $\%$ \\
\hline Chicken & 1,000 & 17 \\
Ginseng & 30 & 0.5 \\
Glutinous rice & 500 & 8.8 \\
Dried Jujube & 50 & 0.9 \\
Garlic & 100 & 1.7 \\
Carrot & 50 & 0.9 \\
Salt & 10 & 0.2 \\
Water & 4,000 & 70 \\
Total & 5,740 & 100 \\
\hline
\end{tabular}


aseptically placed in a sterile bag $(10 \times 15 \mathrm{~cm}$; Sunkyung Co., Ltd., Korea) with $100 \mathrm{~mL}$ of peptone water $(0.1 \%)$ and pummeled in a stomacher (Model 400, Tekmar Co., USA) for $1 \mathrm{~min}$. The stomached solution of sample was used to test the growth of the total bacterial populations in a plate count agar (Difco Laboratories, USA). Plates were incubated at $37^{\circ} \mathrm{C}$ for $48 \mathrm{~h}$, and colonies on plates were manually counted.

\section{Identification of predominant bacteria}

For determination of predominant bacteria in raw materials used for preparing ginseng chicken porridge, identification test by $16 \mathrm{~S}$ rDNA was performed using the method of Edwards et al. (1989). Bacterial genomic DNA was extracted from isolated colony using a genomic DNA isolation kit (MPBiomedicals LLC, USA). The extracted DNA was purified using a QIA quick DNA purification kit (Qiagen, USA). Amplification of 16S rRNA gene was carried out with PCR reactions using 2 universal primers; 27F (5'-AGAGTTTGATCTGGCTCAG-3') and 1492R (5'-ACGGTACCTTGT-TACGACTT-3'). PCR products were purified using the QIA quick Gel Extraction Kit. The purified products were sequenced at Solgent Inc. (Daejeon, Korea) using an ABI3730XL automatic DNA sequencer. DNA sequences of 16S rRNA gene were analyzed using software from the BLASTN program (National Center for Biotechnology Information, 2009).

\section{Bacterial growth test for the evaluation of steriliza- tion}

For the determination of the survival of bacteria in gamma-irradiated raw materials and final product of ginseng chicken porridge prepared with irradiated materials, bacterial growth test was performed by the guideline suggested from Korea Food and Drug Administration (KFDA, 2010), which is used for the sterility test for bacterially decontaminated food products such as retort pouch, and sterilized food can or cooked rice. In brief, $5 \mathrm{~g}$ of sample was aseptically placed in a sterile bag with $45 \mathrm{~mL}$ of phosphate buffered saline (pH 7.4) and pummeled in the stomacher for $20 \mathrm{sec}$. One $\mathrm{mL}$ of the stomached solution was individually put into 3 test tubes with $9 \mathrm{~mL}$ of thioglycollate medium (Difco Laboratories, USA). The tubes incubated at $35^{\circ} \mathrm{C}$ for $48 \mathrm{~h}$ and the changes of the color of the medium were observed. Any tubes with yellowish color in all 3 tubes were regarded as no sterilized samples, and all 3 tubes with no changes of color were considered as sterilized sample.

\section{Sensory evaluation}

Sensory evaluation of the samples was conducted by 10 panels trained according to the method described by Han et al. (2011). Sensory scores of samples were referred to using a 7 point descriptive scale where $1=$ extremely dislike or extremely weak to $7=$ extremely like or extremely strong. Prior to evaluation, about $200 \mathrm{~g}$ of samples were put into a white soup bowl with a cap and heated in a cooker (NU-VU ES-3 cooker, Menominee, USA) at $50^{\circ} \mathrm{C}$ for $10 \mathrm{~min}$. Samples labeled randomly were served to panels.

\section{Measurement of lipid oxidation}

Lipid oxidation was determined using the method of Ahn et al. (1999), which was based on the measurement of 2-thiobarbituric acid reactive substances (TBARS). Sample $(2 \mathrm{~g})$ was homogenized in a $50 \mathrm{~mL}$ centrifuge tube with $50 \mathrm{uL}$ of butylated bydroxyanisol (7.2\% in ethanol) and $20 \mathrm{~mL}$ of distilled water, using a homogenizer (Silentcrusher M, Heidoph Co., Ltd., Germany). One $\mathrm{mL}$ of homogenate was mixed with $1 \mathrm{~mL}$ of $20 \mathrm{mM}$ 2-thiobarbituric acid ( $15 \%$ in trichloroacetic acid solution), heated in boiling water for $15 \mathrm{~min}$, and centrifuged for $20 \mathrm{~min}$ at 2,500 $\times$ g, using a centrifuger (UNION $5 \mathrm{KR}$, Hanil Science Industrial, Co. Ltd., Korea). The absorbance of the supernatant was measured at $532 \mathrm{~nm}$ by a spectrophotometer (UV 1600 PC, Shimadzu, Japan) and the resulting value was calculated as $\mathrm{mg}$ malondialdehyde $/ \mathrm{kg}$.

\section{Statistical analysis}

Samples were analyzed in triplicate and each experiment was performed 5 times. The results were presented as mean \pm standard deviation. All data were analyzed by the general linear model procedures of SPSS statistical package (Windows ver. 10.0, SPSS Inc., USA, 2009). Duncan's multiple range test was used to compare means and significance which was established at $p<0.05$.

\section{Results and Discussion}

\section{Microorganisms contaminated in raw materials}

Table 2 shows the level of microorganisms contaminated in raw materials used for the preparation of ginseng chicken porridge. The initial contamination level of microorganisms of raw chicken meat as major material was 3.4 Log CFU/g. Among those materials, the highest contamination of microorganisms was ginseng of $4.7 \mathrm{Log} \mathrm{CFU} / \mathrm{g}$. Other raw materials such as glutinous rice, carrot, garlic and jujube were ranged from $2.3 \mathrm{Log} \mathrm{CFU} / \mathrm{g}$ to $3.5 \mathrm{Log}$ 
Table 2. Microorganisms detected and the initial levels contaminated in the raw materials using for ginseng chicken porridge, and determination of application of gamma irradiation onto the raw materials

\begin{tabular}{|c|c|c|c|}
\hline Ingredients & $\begin{array}{l}\text { Level of contamination } \\
\text { (Log CFU/g) }\end{array}$ & Major microorganisms & Application of Irradiation \\
\hline Raw chicken & $3.4 \pm 0.1$ & Pseudomonas fragi & $\mathrm{X}^{1)}$ \\
\hline Glutinous rice & $3.1 \pm 0.5$ & Bacillus subtilis & $\mathrm{O}^{2)}$ \\
\hline Garlic & $2.6 \pm 0.1$ & Bacillus subtilis & $\mathrm{O}$ \\
\hline Carrot & $3.5 \pm 0.2$ & Enterobactor faecalis & $X$ \\
\hline Jujube & $2.3 \pm 0.1$ & Bacillus subtilis & $\mathrm{O}$ \\
\hline Ginseng & $4.7 \pm 0.1$ & Bacillus subtilis & $\mathrm{O}$ \\
\hline
\end{tabular}

Mean \pm standard deviation ( $\mathrm{n}=5)$.

${ }^{1)}$ Non-irradiation.

${ }^{2)}$ Irradiation.

Table 3. Changes of total aerobic counts of raw materials used for ginseng chicken porridge by gamma irradiation

\begin{tabular}{ccccc}
\hline \hline \multirow{2}{*}{ Irradiation dose (kGy) } & \multicolumn{2}{c}{ Ingredients (Log CFU/g) } \\
\cline { 2 - 5 } & Glutinous rice & Garlic & Jujube & Ginseng \\
\hline 0 & $3.1 \pm 0.5$ & $2.6 \pm 0.1$ & $2.3 \pm 0.1$ & $4.7 \pm 0.1$ \\
2.5 & $1.6 \pm 0.2$ & $1.2 \pm 0.1$ & $1.3 \pm 0.3$ & $3.1 \pm 0.2$ \\
5.0 & $\mathrm{ND}^{1)}$ & $\mathrm{ND}$ & $\mathrm{ND}$ & $1.5 \pm 0.1$ \\
7.5 & $\mathrm{ND}$ & $\mathrm{ND}$ & $\mathrm{ND}$ & $\mathrm{ND}$ \\
10.0 & $\mathrm{ND}$ & $\mathrm{ND}$ & $\mathrm{ND}$ & ND \\
\hline
\end{tabular}

Mean \pm standard deviation $(\mathrm{n}=5)$.

${ }^{1)}$ Not detected within the detection limit $<10^{1} \mathrm{CFU} / \mathrm{g}$.

Table 4. Bacterial growth test on gamma-irradiated raw materials used for ginseng chicken porridge and the determination of effective sterilizing dose applied for the inactivation of the contaminated microorganisms

\begin{tabular}{|c|c|c|c|c|c|c|}
\hline \multirow{2}{*}{ Ingredients } & \multicolumn{5}{|c|}{ Irradiation dose (kGy) } & \multirow{2}{*}{ Applied dose (kGy) } \\
\hline & 0 & 2.5 & 5 & 7.5 & 10 & \\
\hline Glutinous rice & $(+)^{1)}$ & $(+)$ & $(-)^{2)}$ & $(-)$ & $(-)$ & 5.0 \\
\hline Garlic & $(+)$ & $(+)$ & $(-)$ & $(-)$ & $(-)$ & 5.0 \\
\hline Jujube & $(+)$ & $(+)$ & $(-)$ & $(-)$ & $(-)$ & 5.0 \\
\hline Ginseng & $(+)$ & $(+)$ & $(+)$ & $(+)$ & $(-)$ & 10.0 \\
\hline
\end{tabular}

${ }^{1)}$ Bacterial survival was detected (positive).

${ }^{2}$ Bacterial survival was not detected (negative).

CFU/g. Using 16S rDNA analysis, Pseudomonas fragi in raw chicken and Enterobactor faecalis in carrot were identified as predominant bacteria, respectively (Table 2). Pseudomonas is about $67 \%$ of bacteria contaminated in chicken and is mainly engaged at spoilage during cold storage of meat because this bacteria is psycrotroph ( $\mathrm{Yu}$ et al., 2002). Enterobactor is well observed in fresh agricultural produces such as fruits and vegetables (Yu et al., 2002). These bacteria can be inactivated at ordinary thermal condition (Hassen et al., 2002). Therefore, authors decided that chicken and carrot were excluded from irradiation treatment because these materials were contaminated by gram negative bacteria as the predominant microorganisms and ordinary thermal treatment can inactivate the microorganisms contaminated in these materials.

In glutinous rice, garlic, jujube and ginseng, B. subtilis was identified as mainly contaminated bacteria. In gen- eral, Bacillus species are observed at the grain and dried foods (Grant and G'Appolonia, 1991). These bacteria cannot be inactivated by the ordinary thermal processing below $100^{\circ} \mathrm{C}$ such as the cooking process of ginseng chicken porridge because of thermal stable spores (James, 2001; Jessica et al., 2001). Thus, gamma irradiation was applied to inactivate $B$. subtilis contaminated in glutinous rice, garlic, jujube and ginseng.

\section{Effect of gamma irradiation on decontamination of B. subtilis}

Effect of gamma irradiation on the decontamination of B. subtilis observed in glutinous rice, ginseng, garlic and jujube are provided in Table 3. Growth of microorganisms on plate count agar was not observed in $5 \mathrm{kGy}$-irradiated glutinous rice, garlic and jujube, and in $7.5 \mathrm{kGy}-$ irradiated ginseng $(p<0.05)$. In bacterial growth test for 
the determination of the sterility of irradiated raw materials (Table 4), any growth of bacteria were not observed in 5 kGy-irradiated glutinous rice, garlic and jujube, however the growth of bacteria was observed in $7.5 \mathrm{kGy}$-irradiated ginseng and was not seen in $10 \mathrm{kGy}$-irradiated one $(p<0.05)$. Even though any growth of microorganisms were not observed on the plate count agar of $7.5 \mathrm{kGy}$-irradiated ginseng (Table 3), surviving bacteria can exist and grow below the detection level of $1 \mathrm{Log} \mathrm{CFU} / \mathrm{g}$. Han et al. (2011) and Suzanne et al. (1999) have reported that $\mathrm{D}_{10}$ value of gamma irradiation on spore of Bacillus sp. was in the range of 2.5 to $4 \mathrm{kGy}$, and the value was dependent upon the condition of food and irradiation such as water content, $\mathrm{pH}$, and existence of oxygen, etc. (James, 2001). The determination of the absorbed dose for perfect decontamination could be major factor on the level of microorganisms of final product (Farkas, 2006). Thus, the effective sterilizing dose were determined at $5 \mathrm{kGy}$ on glutinous rice, garlic and jujube and $10 \mathrm{kGy}$ on ginseng (Table 4) and the doses were applied to subsequent experiments. The initial level of contaminated microorganisms is important factor for the determination of irradiation dose (Byun and Lee, 2003). Therefore, the contaminated level of microorganisms should be determined for proper dose to food prior to irradiation treatment.

Table 5 shows the results of the level of microorganisms and bacterial growth test of ginseng chicken porridges prepared with non-irradiated raw materials (control) or with individually irradiated materials. In control, $2.8 \mathrm{Log}$ CFU/g of bacteria was determined $(p<0.05)$, whereas any colony and change of the color were not observed on the plate count agar and in the tube of bacterial growth test, respectively, using samples of ginseng chicken porridge prepared with individually irradiated raw materials. The results indicate that gamma irradiation could be used as decontamination process of raw materials contaminated by bacteria with thermo-stable spores such as Bacillus sp.

\section{Sensory evaluation and lipid oxidation}

In all evaluations except for off-flavor, the scores of both two porridges showed above 6 (Better) (Table 6). Appearance, taste, texture and overall acceptance were not different between both ginseng chicken porridges prepared with irradiated or non-irradiated raw materials (control). These results suggest that ginseng chicken porridge cooked with irradiated glutinous rice, garlic, jujube and ginseng was comparatively well accepted for panels. However, flavor score (6.1) of ginseng chicken porridges prepared with irradiated raw materials was statistically lower than that
Table 5. Level of total aerobic microbes and bacterial growth test of ginseng chicken porridge prepared with individually gamma-irradiated raw materials (Log CFU/g)

\begin{tabular}{ccc}
\hline \hline Items & Control $^{\text {I) }}$ & Irradiated $^{2)}$ \\
\hline Total aerobic microbe & $2.8 \pm 0.5$ & $\mathrm{ND}^{3)}$ \\
Bacterial growth test & $+^{4)}$ & $-{ }^{5)}$ \\
\hline
\end{tabular}

Values are mean \pm standard deviation $(n=5)$

${ }^{1)}$ Ginseng chicken porridge prepared with non-irradiated raw materials.

${ }^{2)}$ Ginseng chciken porridge prepared with irradiated raw materials.

${ }^{3)} \mathrm{ND}$ indicates not detected within the detection limit $<10^{1} \mathrm{CFU} / \mathrm{g}$.

${ }^{4)}$ Bacterial survival was detected (positive).

${ }^{5)}$ Bacterial survival was not detected (negative).

Table 6. Sensory properties of ginseng chicken porridge prepared with individually gamma-irradiated raw materials

\begin{tabular}{ccc}
\hline \hline \multirow{2}{*}{ Attributes } & \multicolumn{2}{c}{ Samples } \\
\cline { 2 - 3 } & Control $^{\mathrm{l}}$ & Irradiated $^{2)}$ \\
\hline Appearance & $6.5 \pm 0.3$ & $6.4 \pm 0.2$ \\
Flavor & $6.7 \pm 0.2^{\mathrm{a}}$ & $6.1 \pm 0.2^{\mathrm{b}}$ \\
Taste & $6.6 \pm 0.4$ & $6.5 \pm 0.3$ \\
Texture & $6.4 \pm 0.2$ & $6.1 \pm 0.4$ \\
Overall acceptance & $6.5 \pm 0.4$ & $6.3 \pm 0.2$ \\
Off-flavor & $1.0 \pm 0.2^{\mathrm{a}}$ & $1.6 \pm 0.1^{\mathrm{b}}$ \\
\hline
\end{tabular}

Values are mean \pm standard deviation $(n=5)$.

${ }^{1)}$ Ginseng chicken porridge prepared with non-irradiated raw materials.

${ }^{2)}$ Ginseng chciken porridge prepared with irradiated raw materials.

${ }^{\mathrm{a}-\mathrm{b}}$ Means with different superscripts in the same row are significantly different $(p<0.05)$.

Table 7. TBARS (mg malondealdehyde/kg) of ginseng chicken porridge prepared with gamma-irradiated raw materials

\begin{tabular}{cc}
\hline \hline Control $^{\text {(1) }}$ & Irradiated $^{2)}$ \\
\hline $0.44 \pm 0.08^{\mathrm{a}}$ & $0.62 \pm 0.13^{\mathrm{b}}$ \\
\hline
\end{tabular}

Values are mean \pm standard deviation $(n=5)$.

${ }^{1)}$ Ginseng chicken porridge prepared with non-irradiated raw materials.

${ }^{2)}$ Ginseng chciken porridge prepared with irradiated raw materials.

${ }^{\mathrm{a}-\mathrm{b}}$ Means with different superscripts in the same row are significantly different $(p<0.05)$.

(6.7) of control $(p<0.05)$. Nevertheless, the score was a sufficiently high value, which was organoleptically acceptable by panels. The score (1.6) of off-flavor of ginseng chicken porridges prepared with irradiated raw materials was also more than that $(1.0)$ of control $(p<0.05)$ but, considering the 7 point scale for sensory evaluation used in this study, the substantial difference between the values of two samples on the sensory estimation of off-flavor might be quite low. This can result in no statistical difference on overall acceptance between both two porridges as observed in Table 6. In addition, formation of off-flavor is asso- 
ciated with the increase of lipid oxidation or the radiolysis of protein and carbohydrate in irradiated materials (Jo and Ahn, 2000). In particular, correlation between sensory result and lipid oxidation of both porridges were considered with the result of TBARS (Table 7). The values of TBARS of ginseng chicken porridges prepared with irradiated raw materials and control were determined as 0.62 and $0.44 \mathrm{mg}$ malondealdehyde $/ \mathrm{kg}$ with statistically differences $(p<0.05)$, even though the differences of the values were not wide. This result could be also used to explain that ginseng chicken porridges prepared with irradiated raw materials on the sensory evaluation of flavor and offflavor was lowly evaluated by the panels. The previous studies have reported the acceleration of lipid oxidation and the generation of off-flavor by ionizing radiation treatment (Byun and Lee, 2003; Jo and Ahn, 2000; Park, 2011a). In this study, any experiment was not conducted to elucidate the correlation between sensory result and radiolysis of ginseng chicken porridges prepared with irradiated raw materials. However, correlation could be inferred from the citation of the previous studies (Ahn et al., 1999; Lee et al., 2008). Increase of lipid oxidation might be induced from the use of irradiated glutinous rice. Han et al. (2011) reported that gamma irradiation caused the increase of lipid oxidation of milk porridge, when $5 \mathrm{kGy}$-irradiated glutinous rice was used. Flavor of irradiated food or irradiated ingredients is one of the very important factors in the acceptance of consumer (Han et al., 2009). Increase of off-flavor can reduce the acceptability of irradiated products (Kim et al., 2008). Therefore, more studies are necessary for improvement of the flavor quality.

As a conclusion, individual gamma-irradiation to each of raw materials was applied to the preparation of ginseng chicken porridge for the development of immunocompromised patient's food. The growth of microorganisms of ginseng chicken porridge prepared with non-irradiated raw materials was observed; whereas no microorganisms in ginseng chicken porridge prepared with individually irradiated raw materials was detected. Sensory results showed that the slight increase of off-flavor was observed in ginseng chicken porridge prepared with individually irradiated raw materials compared with that of the porridge prepared with non-irradiated raw materials. Nonetheless, ginseng chicken porridge cooked with individually irradiated raw materials was comparatively well accepted for panels. Additional food processing method is necessary for improving the flavor quality of ginseng chicken porridge prepared with individually irradiated raw materials.

\section{Acknowledgements}

This research was co-supported by the National Research Foundation in the Nuclear Research \& Development Program and by research grant of International Atomic Energy Agency (IAEA-CRP Research Agreement No. 15760R0).

\section{References}

1. Ahn, D. U., Olson, D. G., Jo, C., Love, J., and Jin, K. (1999) Volatiles production and lipid oxidation in irradiated cooked sausage as related to packaging and storage. J. Food Sci. 64, 226-229.

2. Al-Baali, A. G. A., and Farid, M. M. (2006) Thermal sterilization of food: Historical review, sterilization of food in retort pouches, Springer Science (Business Media LLC), NY, pp. 5-13.

3. ASTM (2004) Practice for use of the alanine-EPR dosimetry system. In: Standards on Dosimetry for Radiation Processing. 2nd ed. ASTM International, West Conshohocken, PA.

4. Bahwere, P., Sadler, K., and Collins, S. (2009) Acceptability and effectiveness of chickpea sesame-based ready-to-use therapeutic food in malnourished HIV-positive adults. Patient Prefer. Adherence 3, 67-75.

5. Bruun L. I., Bosaeus I., Bergstad I., and Nygaard, K. (1999) Prevalence of malnutrition in surgical patients: Evaluation of nutritional support and documentation. Clin. Nutr. 18, 141147.

6. Byun, M. W., and Lee, J. W. (2003) Application of irradiation technology for food safety and security. Food Sci. Ind. 36, 2541.

7. Edington, J., Boorman, J., and Durrant, E. (2000) Prevalence of malnutrition on admission to four hospitals in England. The Malnutrition Prevention Group. Clin. Nutr. 19, 191-195.

8. Edwards, U., Rogall, T., Blcker, H., Emde, M., and Bttger, E. C. (1989) Isolation and direct complete nucleotide determination of entire genes. Characterization of a gene coding for 16S ribosomal RNA. Nucleic Acids Res. 17, 7843-7853.

9. Farkas, J. (2006) Irradiation for better foods. Trends Food Sci. Technol. 17, 148-152.

10. Grant, L. A. and G'Appolonia, B. L. (1991) Effect of lowlevel gamma irradiation on water-soluble non-starchy polysaccharides isolated from hard red spring wheat flour and bran. Cereal Chem. 68, 165-660.

11. Han, I. J., Park, J. S., Choi, J. I., Kim, J. H., Song, B. S., Yoon, Y., Byun, M. W., Chun, S. S., and Lee, J. W. (2009) Change in flavor patterns of gamma irradiated raw oyster and oyster cooking drip determined using an electric nose. Korean $J$. Fish Aquat. Sci. 42, 209-214.

12. Han, I. J., Park, J. N., Park, J. G., Song, B. S., Lee, J. W., Kim, J. H., Ryu, H. S., Park, J. R., and Chun, S. S. (2011) Quality characteristics of milk porridge (Tarakjuk) sterilized with radiation technology. J. Korean Soc. Food Sci. Nutr. 40, 885891.

13. Hassan, Y., Meszaros, L., Simon, A., Tuboly, E., Mohacsi- 
Farkas, C. S., and Farkas, J. (2002) Comparative studies on gamma radiation and high pressure induced effects on minced beef. Acta Aliment. 31, 253-261.

14. James, S. D. (2001) Radiation inactivation of microorganism. In: Food Irradiation, Principles and Applications. Morins, R. A. (ed) John Wiley \& Sons Inc., NY, pp. 23-35.

15. Jessica, L. D., Karen, H., John, K., Ameneh, A., Mark, G., and Peter, A. E. (2001) Bacillus spore inactivation method affect detection assays. Am. Soc. Microbiol. 67, 3665-3670.

16. Jo, C. and Ahn, D. U. (2000) Production volatile compounds from irradiated oil emulsions containing amino acids or proteins. J. Food Sci. 65, 612-616.

17. June, J. H., Yoon, J. Y., and Kim, H. S. (1998) A study on the preference of Korean traditional 'Jook'. Korean J. Dietary Cul. 13, 497-507.

18. KFDA (2010) Food Code. Mun Young Sa, Seoul, Korea. (in Korean)

19. Kim, H. J., Choi, J. I., Park, J. G., Song, B. S., Kim, J. H., Yoon, Y., Kim, C. J., Shin, M. H., Byun, M. W., and Lee, J. W. (2009) Effects of combined treatment of gamma irradiation and addition of fucoidan/laminarin on ready-to-eat pork patty. Korean J. Food Sci. An. 29, 34-39.

20. Kim, M. J., Song, B. S., Park, J. G., Han, I. J., Park, J. N., Choi, J. I., Kim, J. H., Byun, M. W., Lee, K. H., and Lee, J. W. (2008) Sensory quality improvement of gamma-irradiated Kimchi after addition of paprika oleoresin and artificial Kimchi flavor. J. Korean Soc. Food Sci. Nutr. 347, 239-244.

21. Lee, J. W., Kim, J. H., Oh, S. H., Byun, E. H., Yook, H. S., Kim, M. R., Kim, K. S., and Byun, M. W. (2008) Effect of gamma irradiation on viscosity reduction of cereal porridges for improving energy density. Radiat. Phy. Chem. 77, 352-356.

22. Leff, J. W. and Fierer, N. (2013) Bacterial communities associated with the surface of fresh fruits and vegetables. PLOS one 8, e59310.

23. National Center for Biotechnology Information (2009) BLAST Assembled RefSeq Genomes. National Library of Medicine. Available from: http://www.ncbi.nlm.nih.gov/blast/Blast.cgi.
Accessed May 30, 2013.

24. Oh, J. Y., Jee, S. N., Nam, Y., Lee, H., Ryoo, M. I., and Kim, K. D. (2007) Populations of fungi and bacteria associated with samples of stored rice in Korea. Mycobiol. 35, 36-38.

25. Park, J. G., Song, B. S., Kim, J. H., Park, J. N., Han, I. J., Hwang, H. J., Byun, M. W., Cho, H. Y., Kim, Y. W., Mah, J. H., and Lee, J. W. (2010a) Effect of autoclaving and irradiation on microbiological safety and quality of ready-to-eat Bulgogi. Korean J. Food Sci. An. 30, 780-786.

26. Park, J. N., Park, J. G., Han, I. J., Song, B. S., Choi, J. I., Kim, J. H., Sohn, H. S., and Lee, J. W. (2010b) Combined effects of heating and $\gamma$-irradiation on the microbiological and sensory characteristics of Gochujang (Korean fermented red pepper paste) sauce during storage. Food Sci. Biotechnol. 19, 12191225.

27. Richard, J. A. and Walter, J. C. (1998) Nutritional support of pediatric oncology patient. Nutr. 14, 124-129.

28. Shin, E. S., and Ryu, H. S. (2008) Effect of ingredients on in vitro digestibility and physical properties of ginseng-chicken meat porridge. Korean J. Food and Cook. Sci. 24, 273-281.

29. SPSS (1999) SPSS for windows version 10.0, SPSS Inc. Chicago.

30. Suzanne, J. C., Frank, M., Rombouts, K. R., and Marcel, H. Z. (1999) A data analysis of the irradiation parameter $D_{10}$ for bacteria and spores under various conditions. J. Food Protect. 62, 1024-1032.

31. Waitzberg, J. P., Caiaffa, W. T., and Correia, M. I. (2001) Hospital malnutrition; the Brazilian national survey (IBRANUTRI): A study of 4000 patients. Nutrition 19, 603-615.

32. Yu, T. J., Hong, J. H., Kim, Y. B., Lee, H., Kim, Y. A., Hwang, H. J., So, M. H., and Lee, H.G. 2002. Growth and environment of microorganism. In: Food microbiology, Moon Woon Dang, Seoul, Korea, pp. 128-228. (In Korean)

33. Zhang, M., Duan, Z. H., Huan, Y. J., and Tao, Q. (2003) Preparation technology for semi-fluid high-energy food. J. Food Eng. 59, 327-330.

(Received 2013.8.5/Revised 2013.10.29/Accepted 2013.11.12) 